\title{
Influence of viscosity for oil-in-water and water-in-oil nanoemulsions production by SPG premix membrane emulsification
}

\author{
Océane Alliod ${ }^{\mathrm{a}}$, Léa Messager ${ }^{\mathrm{a}}$, Hatem Fessi $^{\mathrm{a}}$, Damien Dupin ${ }^{\mathrm{b}}$, Catherine Charcosset $^{\mathrm{a}, *}$ \\ ${ }^{a}$ Univ Lyon, Université Claude Bernard Lyon 1, CNRS, LAGEP UMR 5007, 43 boulevard du 11 novembre 1918, F-69100, \\ VILLEURBANNE, France \\ ${ }^{b}$ CIDETEC, Paseo Miramón 196, 20014, Donostia-San Sebastián, Spain
}

\begin{abstract}
Oil-in-water and water-in-oil nanoemulsions are interesting carriers for respectively oil soluble and water soluble actives. In this study, oil-in-water $(\mathrm{O} / \mathrm{W})$ and water-in-oil $(\mathrm{W} / \mathrm{O})$ nanoemulsions were prepared by premix membrane emulsification. A coarse emulsion (premix) was injected thanks to a high pressure pump through a Shirasu Porous Glass (SPG) membrane with pore size of $0.5 \mu \mathrm{m}$ in order to reduce and homogenize the droplet size. The effect of viscosities on the pressure and droplet size was investigated: the water phase viscosity by increasing glycerol concentration, the oil phase viscosity with mineral oils of different viscosities and the overall emulsion viscosity by increasing the dispersed phase content of the emulsion. The pressure required to break up the droplets inside the membrane pores $\Delta P_{\text {dis }}$ did not depend on viscosities, while the pressures generated by the flows through the pipe $\Delta P_{\text {pipe }}$ and the membrane $\Delta P_{\text {flow }}$ were proportional to the viscosity of the overall emulsion. W/O nanoemulsions were more difficult to produce and to characterize but thanks to the original set-up working at pressures up to 65 bar and high flowrates, W/O mineral oil nanoemulsions were produced with mean droplets size around $600 \mathrm{~nm}$ and flow rate of $50 \mathrm{~mL} / \mathrm{min}$.

Keywords: Nanoemulsion, Premix membrane emulsification, SPG membrane, Viscosity, Water-in-oil,

Oil-in-water
\end{abstract}

\section{Introduction}

Nanoemulsions, defined by their droplet size which has to be within the submicron range, find applications in cosmetics 1, pharmaceuticals or food industry due to their improved stability and delivery properties 2, 3, 4, 6]. Nanoemulsions can be oil-in-water emulsions $(\mathrm{O} / \mathrm{W})$ with the oil phase dispersed into the water 5 continuous phase, or water-in-oil emulsions (W/O) when the aqueous phase is dispersed into the oily continuous phase. $\mathrm{W} / \mathrm{O}$ nanoemulsions can also be incorporated into a second water phase to create double water-in-oil-in-water emulsions $(\mathrm{W} / \mathrm{O} / \mathrm{W})$ which have several applications in cosmetics or pharmaceutics $[5]$. Then, hydrophillic and hydrophobic actives can be encapsulated within nanoemulsions. Numerous encapsulation technique salso rely on nanoemulsion preparation in order to obtain nanocapsules or nanospheres.

\footnotetext{
${ }^{*}$ Corresponding author. Address: Univ Lyon, Université Claude Bernard Lyon 1, CNRS, LAGEP UMR 5007,43 boulevard du 11 novembre 1918, F-69100, VILLEURBANNE, France. Tel.: +33472431834

Email address: catherine.charcosset@univ-1yon1.fr (Catherine Charcosset)
} 
$\mathrm{W} / \mathrm{O}$ and $\mathrm{O} / \mathrm{W}$ nanoemulsions are produced with the same techniques either low or high energy processes [7. Low energy processes are based on the physicochemical properties of the nanoemulsions and require specific compositions which may not be suitable for cosmetics or pharmaceutical applications. On the contrary, high energy processes like sonication and high pressure homogenization (HPH), are suitable for different types of formulations as intensive disruptive forces breakup the oil and water phases creating droplets 6 . distributions are obtained, and HPH requires several cycles in order to obtain monodispersed droplets.

Membrane emulsification is a more recent process, that also uses mechanical forces but with less energy [8, 9. The process has several advantages such as no temperature increase during emulsification, and low shear rate which gives better stability to shear sensitive actives and the control of the droplet size by the membrane dispersed phase is pushed through the membrane pores and droplets are formed at the membrane/continuous phase interface. DME shows limitations at nano-scale to preserve the monodispersity and small size of the droplets. In addition, flowrates of the dispersed phase are very low [10] which may not be suitable for scale-up.

Another configuration of membrane emulsification has been developped, called premix membrane emulsi25 fication (PME). A coarse emulsion is pushed through the membrane pores, reducing the droplet size and size distribution. The mechanism of droplet formation in PME is related to the break-up of large droplets within the membrane due to wall shear stress inside the membrane pores. The advantages of PME compared to DME 11, 12 are that the flowrate of the product emulsion is generally much higher, higher droplet concentrations are obtained, the mean droplet size is smaller than in DME and the process is easier to control and operate. However, the production of nanoemulsions by membrane emulsification is challenging even with PME [13]. Bunjes et al. prepared nanoemulsions by PME with droplet size lower or around $200 \mathrm{~nm}$ with narrow size distribution with polymeric membranes and SPG membranes for volumes up to $10 \mathrm{~mL}$. 10, 14, 15. In a previous work, we reported the production of $\mathrm{O} / \mathrm{W}$ nanoemulsions by PME and SPG membranes at high flowrate and relatively large volumes up to $500 \mathrm{~mL}[16$.

In both DME and PME, the viscosities of the continuous and dispersed phase are important parameters, although their effect has been investigated by few authors. For example, Vladisavljević et al. studied the viscosity in PME by increasing the dispersed phase content which increased the overall emulsion viscosity [12] or the continuous phase viscosity [17. Both studies were performed at constant pressure and showed that an increase in viscosity led to a decrease in transmembrane flux and to smaller oil droplets due to increase 40 of wall shear stress inside the membrane pores.

Also, in DME, only few studies reported the production of W/O emulsions, mainly micron size emulsions with kerosene as the continuous phase with different types of membranes or surface modifications [18, 19, 20, or with toluene [21]. A study reported the production of $\mathrm{W} / \mathrm{O}$ emulsions suitable for cosmetics or dermatological applications with mineral oil as the continuous phase [22]. For double emulsion production, the first W/O emulsions has always been obtained by a high energy process [12, 13, 23. To our knowledge, no study 
reported the production of $\mathrm{W} / \mathrm{O}$ emulsion by PME. It can be explained by the fact that viscous emulsions generate high pressure through the membrane pores [16] and that $\mathrm{W} / \mathrm{O}$ emulsions are much more viscous than $\mathrm{O} / \mathrm{W}$ emulsions as the oil is the continuous phase.

In the present study, $\mathrm{O} / \mathrm{W}$ and $\mathrm{W} / \mathrm{O}$ nanoemulsions were produced by $\mathrm{PME}$ with a high pressure pump that pushed the premix through the SPG membrane. The resulting pressure $\Delta P_{r}$ was equal to the sum of the flow pressure $\Delta P_{\text {flow }}$, the disruption pressure $\Delta P_{\text {dis }}$ and the pipe pressure $\Delta P_{\text {pipe }}$ :

$$
\Delta P_{r}=\Delta P_{\text {flow }}+\Delta P_{\text {dis }}+\Delta P_{\text {pipe }}
$$

The flow pressure was the pressure necessary to pass the premix emulsion through the very small membrane pores. The disruption pressure $\left(\Delta P_{\text {dis }}\right)$ was the pressure required to break the premix emulsion into smaller droplets and therefore reducing the droplet size [12]. Moreover, the pressure along the pipe from the high pressure pump to the membrane module was dependent on fluid viscosity and therefore had to be taken into account. This pressure was termed pipe pressure $\Delta P_{\text {pipe }}$ and was measured without the membrane. $\Delta P_{\text {flow }}$ and $\Delta P_{\text {dis }}$ are pressures generated by the fluid circulating through the membrane $\Delta P_{\text {membrane }}$ :

$$
\Delta P_{\text {membrane }}=\Delta P_{\text {flow }}+\Delta P_{\text {dis }}
$$

In this study, we investigated the effect of viscosity of the dispersed, continuous phase and overall emulsion, on the production of $\mathrm{W} / \mathrm{O}$ and $\mathrm{O} / \mathrm{W}$ nanoemulsions by PME. The final aim is to optimize the preparation of $\mathrm{W} / \mathrm{O}$ nanoemulsions, which is challenging due to high viscosities involved. For that, $\mathrm{O} / \mathrm{W}$ and $\mathrm{W} / \mathrm{O}$ premixes with different viscosities were produced. The influence of viscosity was investigated by modifying the continuous phase viscosity, the dispersed phase viscosity, and the dispersed phase content, whith all phases and final products being Newtonian fluids. The water phase viscosity was modified by adding glycerol and the oil phase viscosity was modified by using different mineral oils with similar interfacial tension with water. The premixes were pushed through the membrane pores using a high pressure pump in the setup developed previously for $\mathrm{O} / \mathrm{W}$ nanoemulsions production [16]. The influence of the formulation on the resulting pressure and on $\Delta P_{\text {flow }}, \Delta P_{\text {dis }}$ and $\Delta P_{\text {pipe }}$ was investigated. The nanoemulsions obtained were characterized by their mean droplet size and/or size distribution.

\section{Materials and methods}

\subsection{Materials}

Ultrapure water was obtained using a Synergy unit system (Millipore, France). Mineral oil of different viscosities were given by different suppliers: White Mineral Oil (WMO) from Fisher (USA) $\eta=44$ mPa.s (at $25^{\circ} \mathrm{C}$ ), Marcol 52 and Marcol 82 from Exxon mobil (France) respectively $\eta=14.1 \mathrm{mPa} . \mathrm{s}$ and $\eta=24.1 \mathrm{mPa} . \mathrm{s}$ (at $25^{\circ} \mathrm{C}$ ). Other products were glycerol from Roth (Germany), Tween 20 and Span 80 from Sigma Aldrich 75 (France) and Derquim+ from Derquim (Spain). 


\subsection{Experimental set-up}

The experimental set-up used for the preparation of nanoemulsions by PME is shown in Figure 1 . The set-up was composed of a high pressure benchtop single cylinder pump BTSP 500-5 (Floxlab, Nanterre, France). The pump is made of high grade stainless steel and was equipped with a pressure sensor $( \pm 0.1$ bar), two pneumatic valves for tank feeding and outlet delivery, a control panel and a storage tank of 500 $\mathrm{mL}$. Pressurization was obtained via a motor-driven piston. A computer was connected to the pump for data acquisition. The flowrate, pressure and volume injected were recorded every second with the software. The maximum pressure delivered by the pump was 344 bar and flowrate $200 \mathrm{~mL} / \mathrm{min}$.

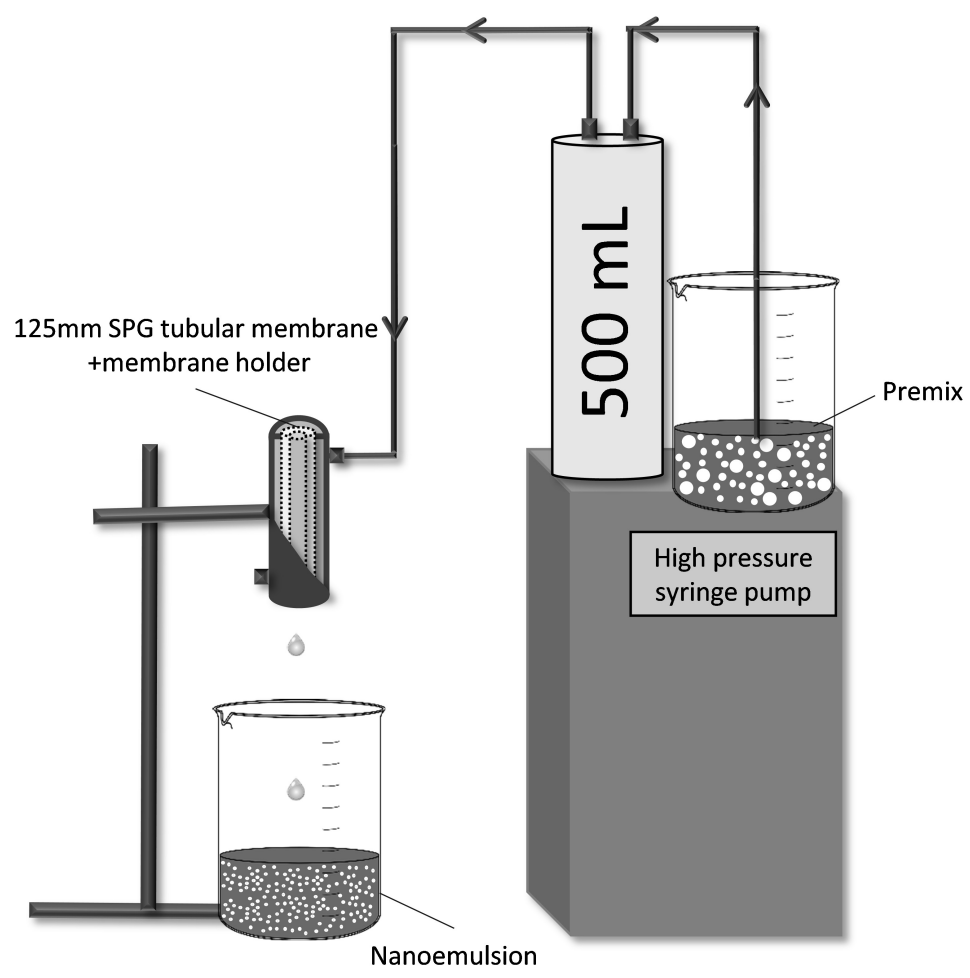

Figure 1: Experimental set-up of the high syringe pump with membrane holder and SPG membrane

For each premixes, the set-up resistance to the flow without the membrane module was tested at different flowrates between 10 and $200 \mathrm{~mL} / \mathrm{min}$ and the resulting pressure, $\Delta P_{\text {pipe }}$, was measured.

\subsection{Membranes}

Hydrophilic and hydrophobic SPG membranes were provided by SPG Technology Co. Ltd (Miyazaki, Japan). Hydrophillic SPG membranes were used for O/W nanoemulsion production and hydrophobic for $\mathrm{W} / \mathrm{O}$ nanoemulsions. Both membranes are first produced the same way, hydrophobic membranes are then obtained thanks to a special coating made by the supplier. The membranes are tubular with an inner diameter of $8.5 \mathrm{~mm}$, thickness of $0.8 \mathrm{~mm}$ and length of $125 \mathrm{~mm}$. In all experiments, the membrane length was $125 \mathrm{~mm}$ and the mean pore size $0.5 \mu \mathrm{m}$. The membranes were able to resist to transmembrane pressure up to 65 bar. 


\begin{tabular}{|l|c|c|c|c|}
\hline & \multicolumn{3}{|c|}{ Content in (w/w\%) } & Dynamic \\
\cline { 2 - 4 } & WMO & Marcol 82 & Marcol 52 & viscosity at 25ㄷ \\
\hline WMO & $100 \%$ & $\mathrm{X}$ & $\mathrm{X}$ & 44.1 \\
\hline Marcol 82 & $\mathrm{X}$ & $100 \%$ & $\mathrm{X}$ & 24.1 \\
\hline WMO+ M82 & $50 \%$ & $50 \%$ & $\mathrm{X}$ & 30.6 \\
\hline Marcol 52 & $\mathrm{X}$ & $\mathrm{X}$ & $100 \%$ & 9.87 \\
\hline
\end{tabular}

Table 1: Composition and dynamic viscosities of oils used to study the influence of dispersed phase viscosity

The membrane module used was a tubular module supplied by SPG Technology. This cross-flow tubular module was adapted to be used in PME. The premix was pushed from the external part of the tube to the internal part. The effective length of the membranes was reduced due to sealing rings placed at both ends of the membrane tube. Therefore, the effective length was $115 \mathrm{~mm}$ and the effective membrane area was 30.70 $\mathrm{cm}^{2}$.

\subsection{Formulation of nanoemulsions}

Oil phases compositions studied and viscosities measured with the method detailed in the following viscosity measurement part, are described in Table 1.

For $\mathrm{O} / \mathrm{W}$ nanoemulsions, ultrapure water with or without glycerol was used as the continuous phase and mineral oils as the dispersed phase. The required HLB (RHLB) of mineral oils were all the same and given by the supplier as RHLB $=10$. The surfactant system chosen to stabilize the nanoemulsions was Tween 20 , $\mathrm{HLB}=16.7$, as the hydrophilic surfactant and Span $80, \mathrm{HLB}=4.3$, as the hydrophobic surfactant. In most experiments, the composition (in weight percentage of the total emulsion) was for the continuous phase, 2.3 \% Tween 20 and $85 \%$ water, and for the dispersed phase $2.7 \%$ Span 80 and $10 \%$ oil. The overall surfactant concentration was then $5 \%$. The surfactants and high concentrations were chosen to ensure that the newly formed droplets were immediately covered with surfactants, hence preventing the increase in droplet size.

Three oils with different viscosities were investigated, WMO, Marcol 82 and Marcol 52 and a mixture of WMO and Marcol 82 (Table 1). The influence of oil concentration was investigated at 5, 10, 20, 25 and 30 $\%$ for Marcol 82. The surfactant concentration to oil concentration ratio was kept constant at 0.5 , so the total surfactant concentration in the formulation was respectively $2.5,5,10,12.5$ and $15 \%$. In addition, the influence of glycerol concentration was investigated at 10, 25, 50 and $62.5 \%$ of the aqueous phase completed with water up to $85 \%$ of the total formulation.

For W/O nanoemulsions, mineral oils as supplied or mixtures of mineral oils were used as the continuous phase and ultrapure water with or without glycerol as the dispersed phase. RHLB of mineral oils were all the same and given by the supplier as $\mathrm{RHLB}=5$. In most experiments, the composition (in weight percentage of the total emulsion) was for the continuous phase, $0.28 \%$ Tween 20 and $85 \%$ oil, and for the dispersed phase $4.72 \%$ Span 80 and $10 \%$ water. The overall surfactant concentration was then $5 \%$. The oil phases investigated were pure WMO, Marcol 82 or Marcol 52 or a mixture of WMO and Marcol 82 (Table 1). 
The influence of water concentration was investigated at 1, 5, 10 and $15 \%$. The surfactant concentration to oil concentration ratio was kept constant at 0.5 , so the total surfactant concentration in the formulation was respectively $0.5,2.5,5$ and $7.5 \%$. In addition, the influence of glycerol concentration was investigated at $25,50,75$ and $100 \%$ of the aqueous phase completed with water up to $10 \%$ of the total formulation. light scattered as a laser beam passes through a dispersed particulate sample. The Mie scattering theory was used, with a refractive index and an absorption index set at 1.47 and 0.005 for the oil phase, respectively and 1.33 and 0.005 for the water phase. For $\mathrm{O} / \mathrm{W}$ nanoemulsions, the continuous phase was ultrapure water and 
155 for $\mathrm{O} / \mathrm{W}$, Marcol 82. Before measuring the droplet size of $\mathrm{W} / \mathrm{O}$ nanoemulsions the instrument, including injection line and measurement cell, was emptied, cleaned with surfactant, filled with ethanol, dried and fill with oil. The same procedure was used to clean the apparatus after measurement.

The results were expressed by $D_{50}$ the mean droplet diameter for which $50 \%$ of droplets in volume are below this size, similarly $90 \%$ lie below $D_{90}$ and $10 \%$ below $D_{10} \cdot D_{90}$ and $D_{10}$ giving information about the sample dispersity. The closest they are to the $D_{50}$ the more monodisperse the distribution is.

All measurements were done in triplicate, the values reported were the average of the three measurements.

\subsection{Viscosity measurements}

For the investigation of the effect of oil concentration, the dynamic viscosity of the emulsions, continuous phase and dispersed phase were measured. The measurements were realized using a rheometer MCR 302 equipped with the CP50 module and the software Rheocompass (Anton Paar, France) at $25^{\circ} \mathrm{C}$. Viscosity was measured with a shear rate from 0 to $100 \mathrm{~s}^{-1}$.

\section{Results and discussion}

In this section, we first measured the pressure generated through the pipe connecting the pump to the membrane module. This pressure is then substrated to the resulting pressure measured during the preparation of nanoemulsions to obtain the membrane pressure. Then, results obtained for $\mathrm{O} / \mathrm{W}$ and $\mathrm{W} / \mathrm{O}$ nanoemulsions are presented including the effect of continuous phase viscosity, dispersed phase viscosity and dispersed phase content, which determines the viscosity of the overall emulsion, on membrane pressure and droplet size. Also, for both $\mathrm{O} / \mathrm{W}$ and $\mathrm{W} / \mathrm{O}$ nanoemulsions, the disruption pressure and flow pressure were determined from the influence of the cycle number on the membrane pressure.

175 3.1. Influence of viscosity on $\Delta P_{\text {pipe }}$

The pressure generated by the pump through the pipe connecting the pump to the membrane module was measured for different premixes at flowrates from 10 to $100 \mathrm{~mL} / \mathrm{min}$. For that, the premix was injected through the pipe without the membrane module being connected. The resulting pressure measured was then equal to $\Delta P_{\text {pipe. }}$ All premixes tested were Newtonian and the flows through the pipe were laminar. The hydraulic resistances measured were specific to pipe used (length, diameter, elbows).

Figure 2 shows the pressure variation with flowrate for different $\mathrm{O} / \mathrm{W}$ premixes. Two types of premixes were prepared: premixes with water as the continuous phase (without glycerol) and different Marcol 82 content (from 10 to 30\%) and premixes with 10\% Marcol 82 and different contents of glycerol in the water phase (10 to $62.5 \%$ glycerol). $\Delta P_{\text {pipe }}$ was found proportional to the flowrate, as predicted by the Poiseuille equation, with the hydraulic resistance dependent on the premix composition. Figure 3 shows the variation of the hydraulic resistance through the pipe versus the premix viscosity. As expected from Poiseuilles law, the hydraulic resistance was proportional to the premix viscosity. Figure 3 also includes hydraulic resistances obtained with $\mathrm{W} / \mathrm{O}$ premixes in a similar way as $\mathrm{O} / \mathrm{W}$ premixes. 
For $\mathrm{O} / \mathrm{W}$ premixes, the pressure generated through the pipe was in the range 0-3 bar, except for the higher content of glycerol (up to 6 bar). For W/O premixes, higher values were obtained, from 2 to 18.6 bar. In the following parts, to obtain the pressure generated through the membrane $\Delta P_{\text {membrane }}$ during the preparation of nanoemulsions, $\Delta P_{\text {pipe }}$ was subtracted from the resulting pressure $\Delta P_{r}$.

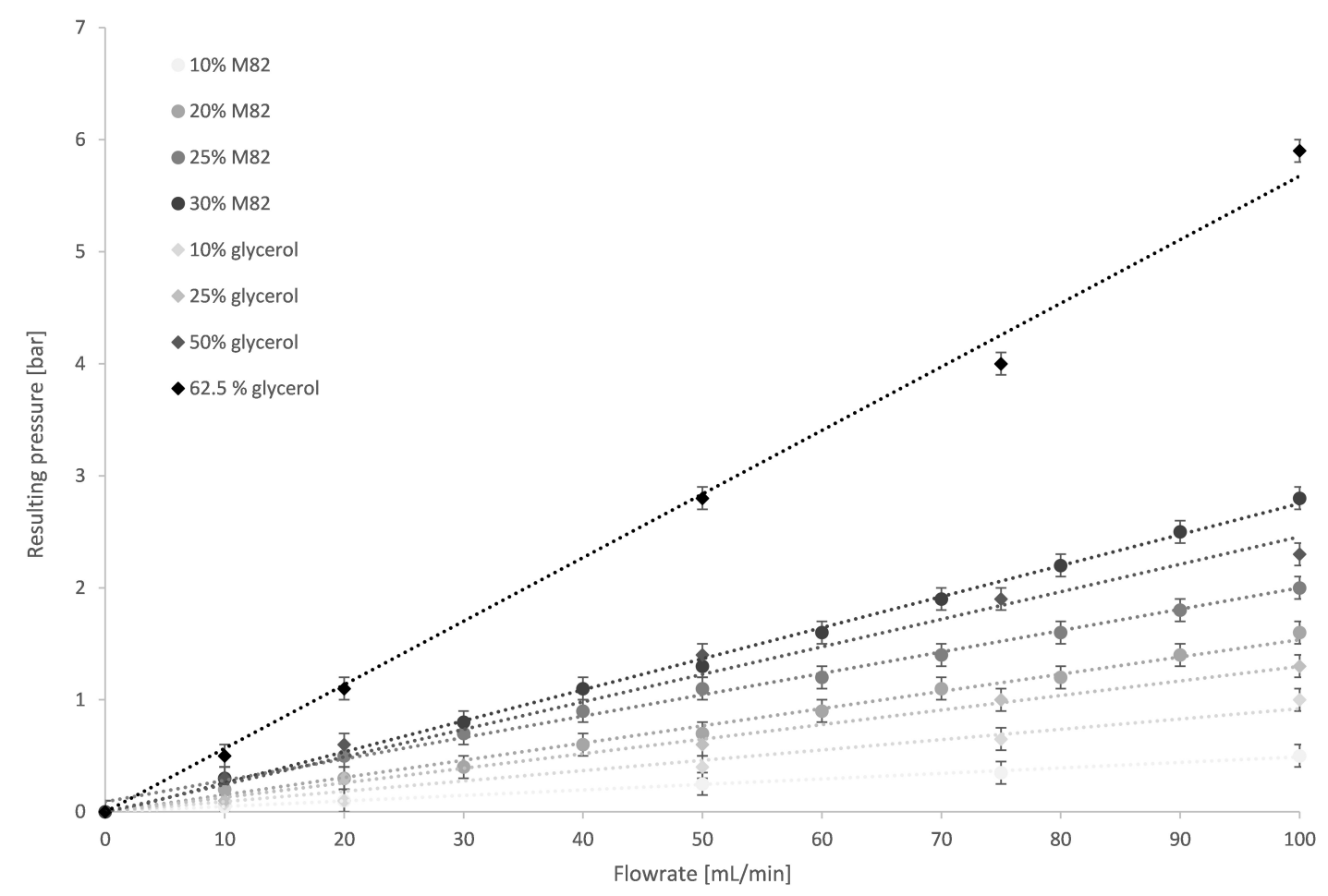

Figure 2: Resulting pressure, $\Delta P_{\text {pipe }}$, without membrane module for different $\mathrm{O} / \mathrm{W}$ emulsions at flowrate from 10 to $100 \mathrm{~mL} / \mathrm{min}$

\section{2. $O / W$ nanoemulsions}

In this section, we prepared $\mathrm{O} / \mathrm{W}$ nanoemulsions with different compositions as described in Materials and Methods. The influence of the continuous phase viscosity, dispersed phase viscosity as well as the dispersed phase content on the droplet size and membrane pressure was investigated. Also, $\Delta P_{\text {dis }}$ and $\Delta P_{\text {flow }}$ were determined from the effect of the cycle number on the membrane pressure.

\subsubsection{Influence of the continuous phase viscosity}

The effect of the continuous phase viscosity was investigated at four different glycerol concentrations in the continuous water phase, 10,25, 50,62,5\%, corresponding respectively to aqueous phase viscosities of $1.14,1.79,5.00$ and $10.5 \mathrm{mPa}$.s. It was observed that at higher glycerol concentrations, the emulsion was non-Newtonian. The oil type, oil concentration and surfactant concentration were the same: 10\% Marcol 82 and $5 \%$ total surfactant concentration. Figure 4 shows the membrane pressures measured at various flowrates. 


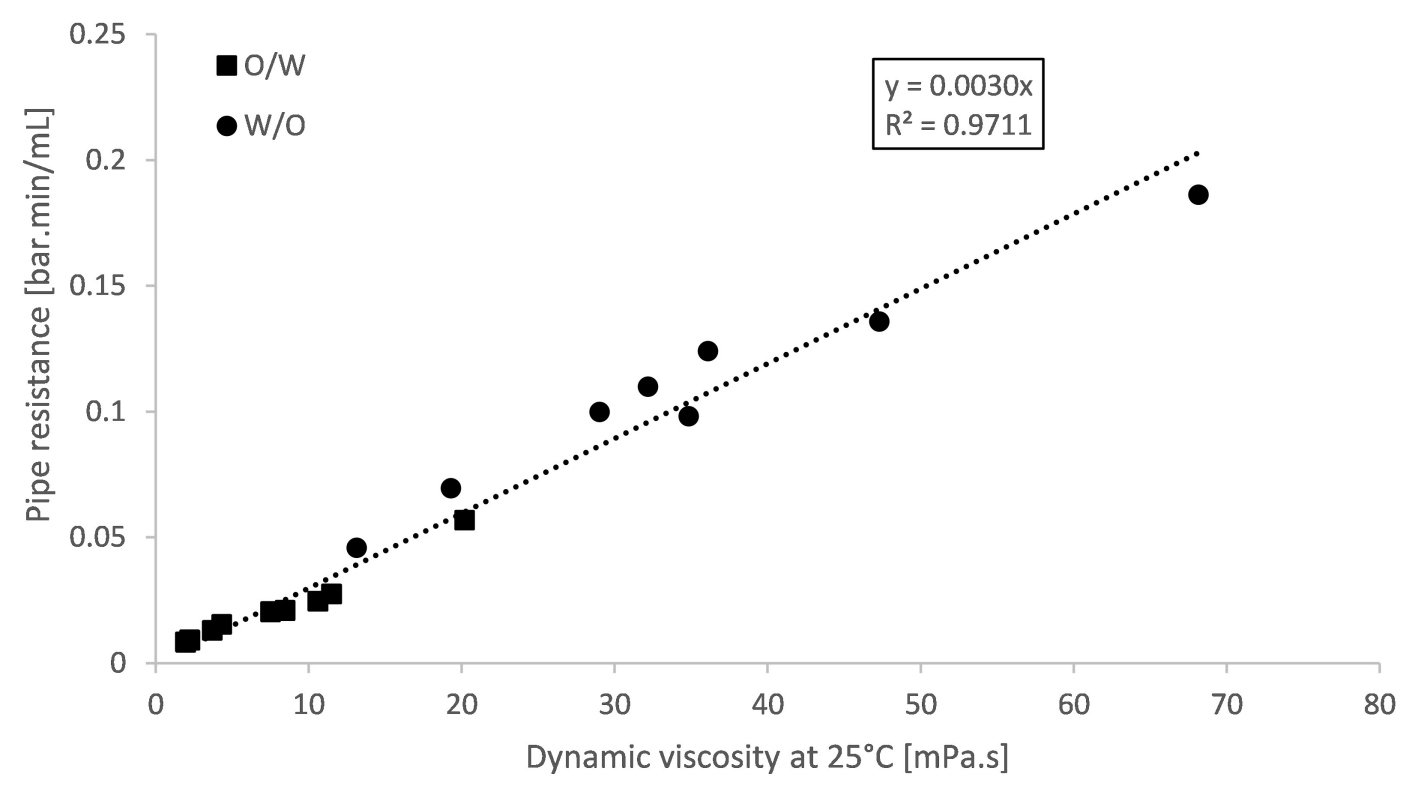

Figure 3: Slope of the resulting pressure, $\Delta P_{\text {pipe }}$ with flow rate as a function of viscosity for $\mathrm{O} / \mathrm{W}$ and $\mathrm{W} / \mathrm{O}$ emulsions of different composition

The continuous phase viscosity had no influence on the membrane pressure at low flowrates (below $50 \mathrm{~mL} / \mathrm{min}$ ), and at higher flowrates and low continuous phase viscosity (below $1.79 \mathrm{mPa} . \mathrm{s}$ ). In these conditions, the flow pressure was relatively low so the membrane pressure was mainly attributed to the disruption pressure. At higher flowrates and continuous phase viscosities, the membrane pressure increased when increasing the continuous phase viscosity. At $100 \mathrm{~mL} / \mathrm{min}$, the membrane pressure was 20.6 bar for a continuous phase viscosity of $10.5 \mathrm{mPa} . \mathrm{s}$ and around two times less 11.2 bar at 1.14 and $1.79 \mathrm{mPa} . \mathrm{s}$. Indeed, the flow pressure $\Delta P_{\text {flow }}$ is proportional to viscosity [12]. At higher viscosity of the continuous phase, the flow pressure was then much higher and might be in the same range as the disruption pressure.

The influence of the continuous phase viscosity on the droplet size is presented in Figure 5 The mean droplet size decreased when increasing the viscosity of the continuous phase, as the shear stress within the pores increased, leading to a more significant size reduction [17. At high viscosities, the shear stress obtained was very high, and very small droplets were obtained with $D_{50}$ equal to $293 \mathrm{~nm}$, which was $59 \%$ smaller than the membrane pore size. Figure 5 also shows that the viscosity of the overall emulsion increased proportionally to the continuous phase viscosity. It remains unclear whether the viscosity of the continuous phase, or the viscosity of the overall emulsion or both influence the membrane pressure and droplet size. This will be discussed in a following section.

\subsubsection{Influence of the dispersed phase viscosity}

The influence of the dispersed phase viscosity on the membrane pressure and droplet size was investigated with four different oils: three mineral oils from different supppliers used as received: WMO, Marcol 82 and 


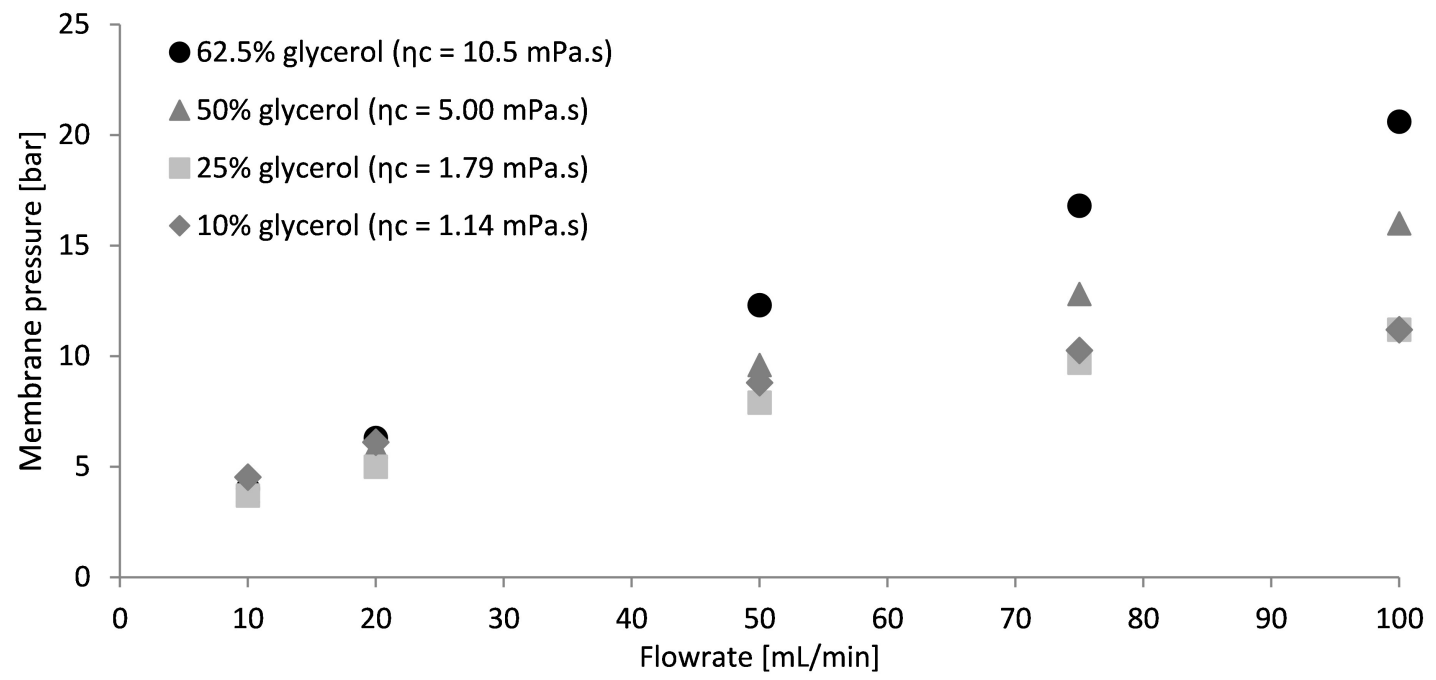

Figure 4: Membrane pressure variation with flowrate from 10 to $100 \mathrm{~mL} / \mathrm{min}$ at four different concentrations in glycerol in the water phase and at $10 \%$ of Marcol 82 and $5 \%$ surfactant

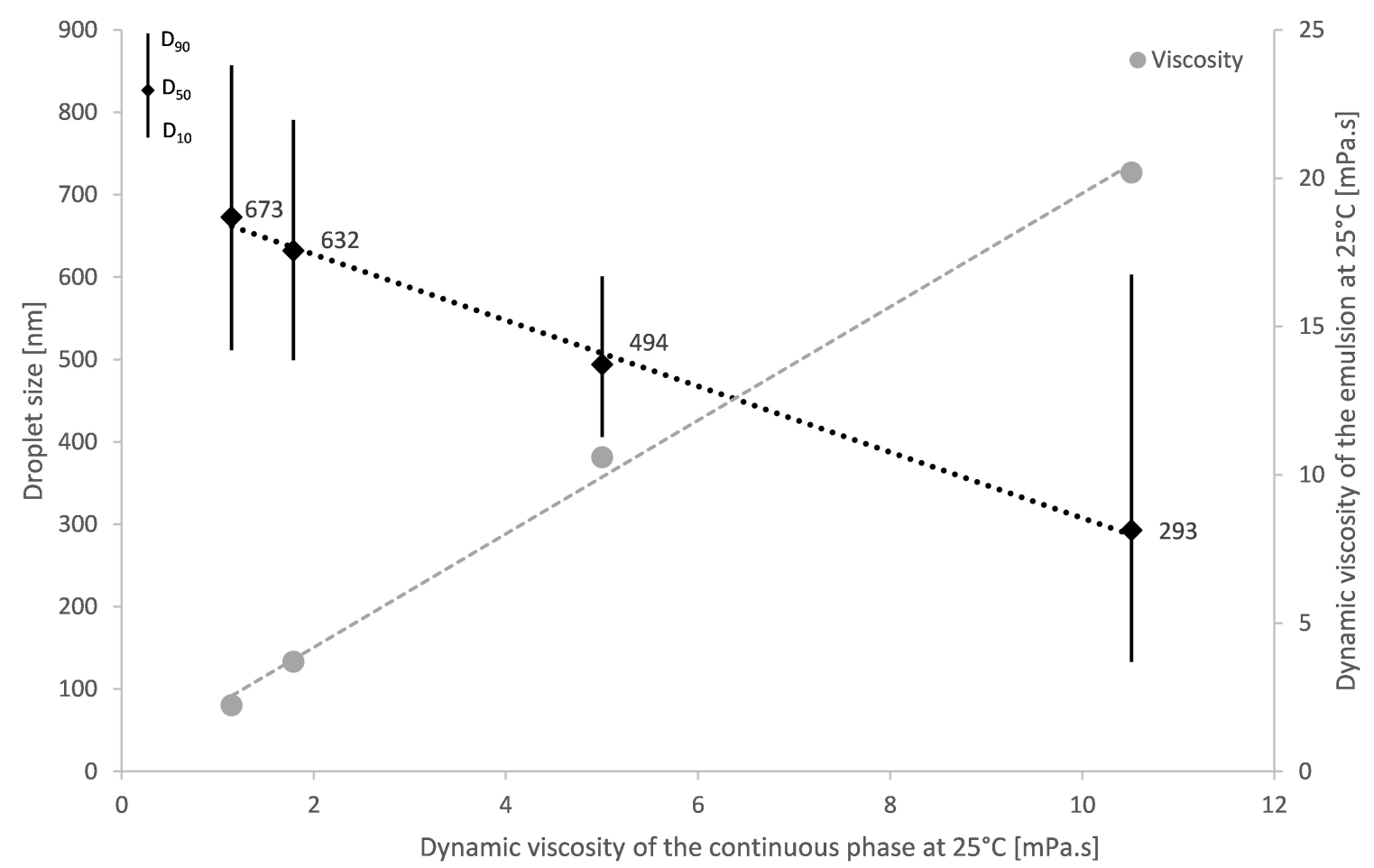

Figure 5: Droplet size and viscosity of the emulsion versus the viscosity of the continuous phase at $10 \%$ of Marcol 82 and $5 \%$ surfactant and a flowrate of $100 \mathrm{~mL} / \mathrm{min}$

Marcol 52 and a mix of 50\%/50\% WMO and Marcol 82 (Table 1). The oil concentration and surfactant 225 concentration were kept constant at $10 \%$ and $5 \%$, respectively. The viscosities of the four emulsions were the 
same (4.3 mPa.s).

For the different oils, the membrane pressure and droplet size as a function of flowrate are presented in Figure 6. The membrane pressure did not change with the dispersed phase viscosity at low flowrates. However, at higher flowrates, from $75 \mathrm{~mL} / \mathrm{min}$, the membrane pressures were slightly higher for the more viscous oils. The difference between the less viscous oil Marcol $52(\eta=9.87 \mathrm{mPa} . \mathrm{s})$ and the more viscous WMO $(\eta=44.1 \mathrm{mPa} . \mathrm{s})$ which is more than four times more viscous, was of $\Delta P_{r} W M O-\Delta P_{r} M 52=$ 20.5-18.6=1.9 bar. This effect might be more important at higher flowrate or higher oil content.

The similar viscosities of the overall emulsions cannot be the reason of the increase in membrane pressure for the more viscous oils. This effect may be explained by the critical capillary number for breaking a drop in a T-junction (which is a simple model of a membrane pore) which is proportional to a dimensionless constant $\alpha$, function of the viscosity difference between the dispersed and continuous phases and the geometry of the channel [26]). As the oil viscosity increased, the viscosity difference between the two phases increased and so the capillary number. Droplet break-up became more difficult so the pressure needed for oil droplets disruption in the membrane pores $\Delta P_{\text {dis }}$ became higher.

Moreover, the droplet size distribution did not change with the dispersed phase viscosity (Figure 6) at these experimental conditions. Figure 6 also shows a slight decrease in droplet size versus flowrate, as observed in our previous study with $10 \%$ ethylhexyl palmitate (EHP) as the dispersed phase and $5 \%$ total surfactant concentration [16].

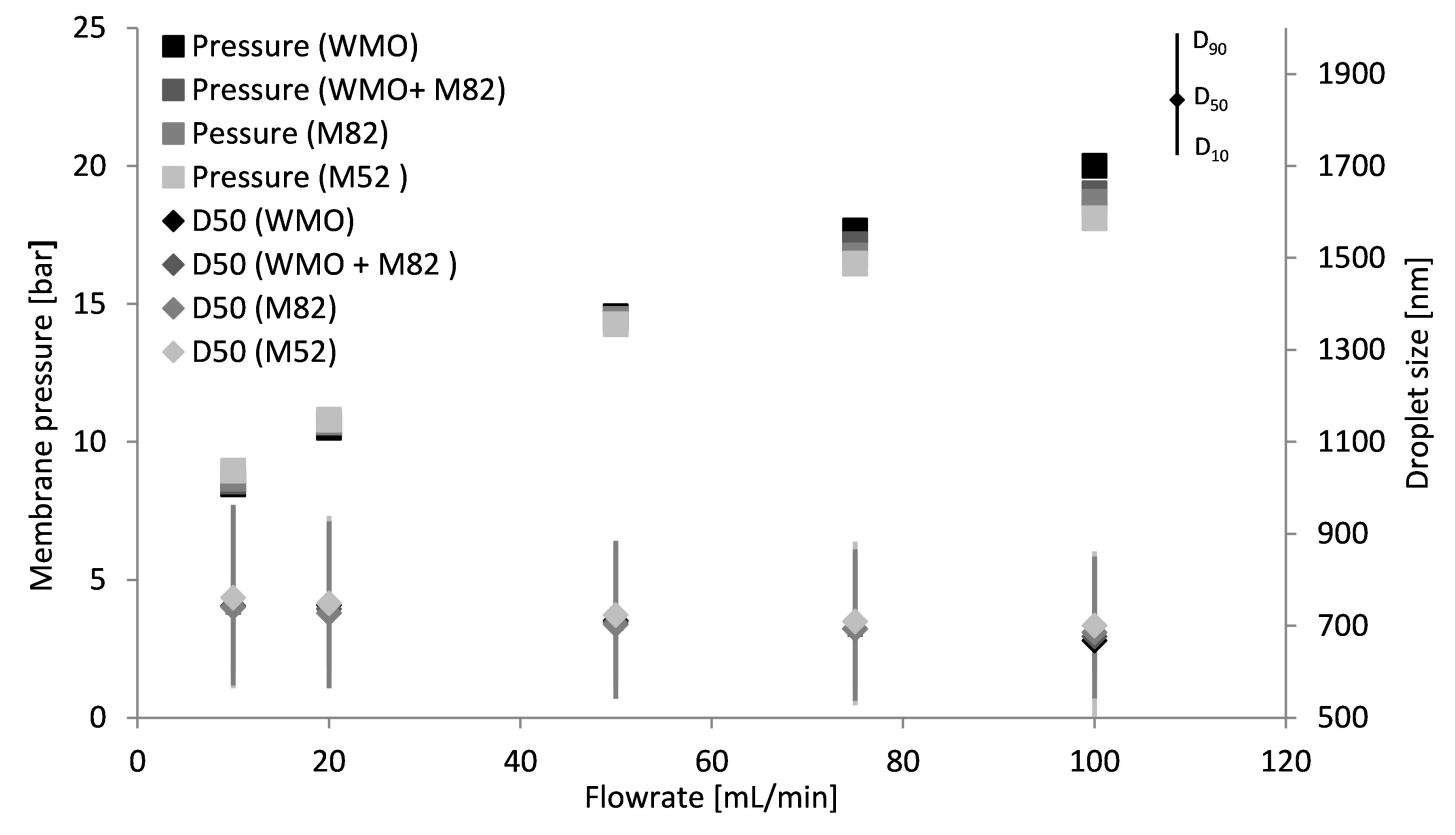

Figure 6: Membrane pressure and droplet size at different flowrates with different oils or oil mix at $10 \%$ and $5 \%$ overall surfactant concentration 


\subsubsection{Influence of the dispersed phase content}

at four Marcol 82 concentrations 10, 20, 25 and 30\% at $100 \mathrm{~mL} / \mathrm{min}$. Higher oil concentrations were not tested because of the non-Newtonian behavior of the emulsions. The viscosity of the overall emulsions increased with the amount of oil, 4.3, 7.05, 10.85 and $17.85 \mathrm{mPa} . \mathrm{s}$ for the 10,20,25, 30\% oil concentrations, respectively.

As explained in Materials and Methods, the surfactant concentration based on the amount of oil was

These two last effects could contribute to a decrease of the droplet size.

\subsubsection{Experimental determination of $\Delta P_{\text {flow }}$ and $\Delta P_{\text {dis }}$}

To obtain the values of $\Delta P_{\text {flow }}$ and $\Delta P_{\text {dis }}$, repeated cycles were realized. For that, the premix was passed first through the membrane, and then the nanoemulsions obtained was passed again during three cycles at

: four Marcol 82 concentrations 10, 20, 25,30\%. The viscosity of the emulsions remained nearly constant with the number of cycles, with a slight decrease from the first pass to the second pass as the droplet size was reduced. The membrane pressures measured during each cycle are reported in Figure 8.

The membrane pressures were higher during the first cycles, but stabilized after first pass. For all cycles, 


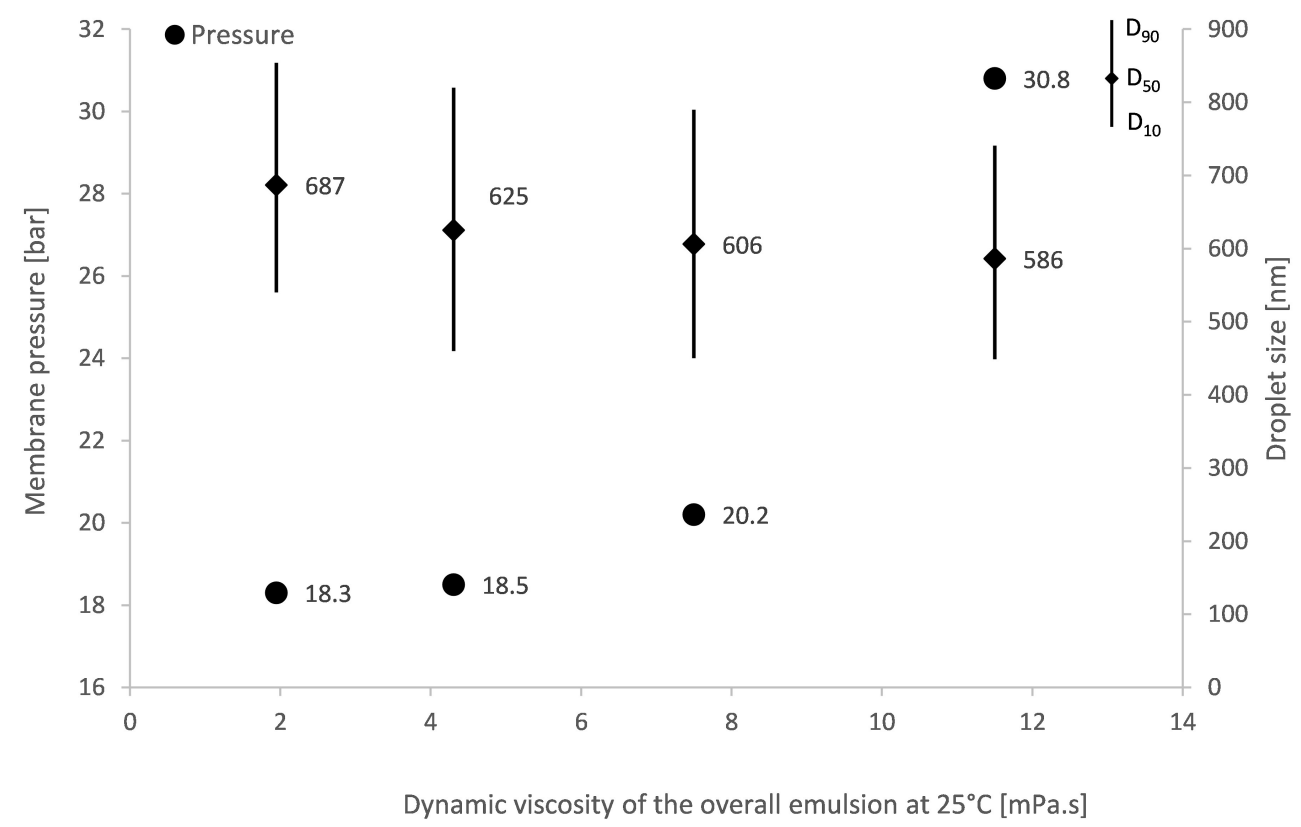

Figure 7: Membrane pressure and droplet size as a function of dynamic emulsion viscosity for different oil contents at 100 $\mathrm{mL} / \mathrm{min}$

the membrane pressure stabilized at a higher value for emulsions with a higher oil content. During the first cycle, the membrane pressure stabilized at 30.8 bar and 18.3 bar for emulsions containing $30 \%$ and $10 \%$ Marcol 82, respectively. During the fourth cycle, the membrane pressure stabilized at 14.5 bar and 3.7 bar for $30 \%$ and $10 \%$ Marcol 82, respectively. The membrane pressure remained constant after the first cycles as no more droplet disruption occurred in the membrane pores, which means that after the first cycles $\Delta P_{d i s}=0$ therefore $\Delta P_{m}=\Delta P_{\text {flow }}$.

The variations of $\Delta P_{\text {dis }}$ and $\Delta P_{\text {flow }}$ with the overall emulsion viscosity are presented in Figure $9 . \Delta P_{m 1}$ is the membrane pressure obtained during the first cycle. The stabilized pressure value $\Delta P_{m f}$ was calculated as the average membrane pressure values of the two last cycles, cycles $n^{\circ} 3$ and $n^{\circ} 4$. As said previously, disruption occurs mainly during the first cycle, whereas most of the droplets do not undergo any droplet disruption for the following cycles. So, $\Delta P_{d i s}=\Delta P_{m 1}-\Delta P_{m f}$ and $\Delta P_{\text {flow }}=\Delta P_{m f}$.

Figure 9 shows that $\Delta P_{\text {dis }}$ was independent of the overall emulsion viscosity. It means that the energy required for droplet disruption was the same for the various oil contents, if the oil to surfactant ratio was kept constant. As expected, $\Delta P_{\text {flow }}$ was proportional to the emulsion viscosity 22 .

\subsection{W/O nanoemulsions}

In this section, $\mathrm{W} / \mathrm{O}$ nanoemulsions were prepared at different compositions by varying the viscosity of the continuous phase, viscosity of the dispersed phase and water content, which modifies the overall emulsion 


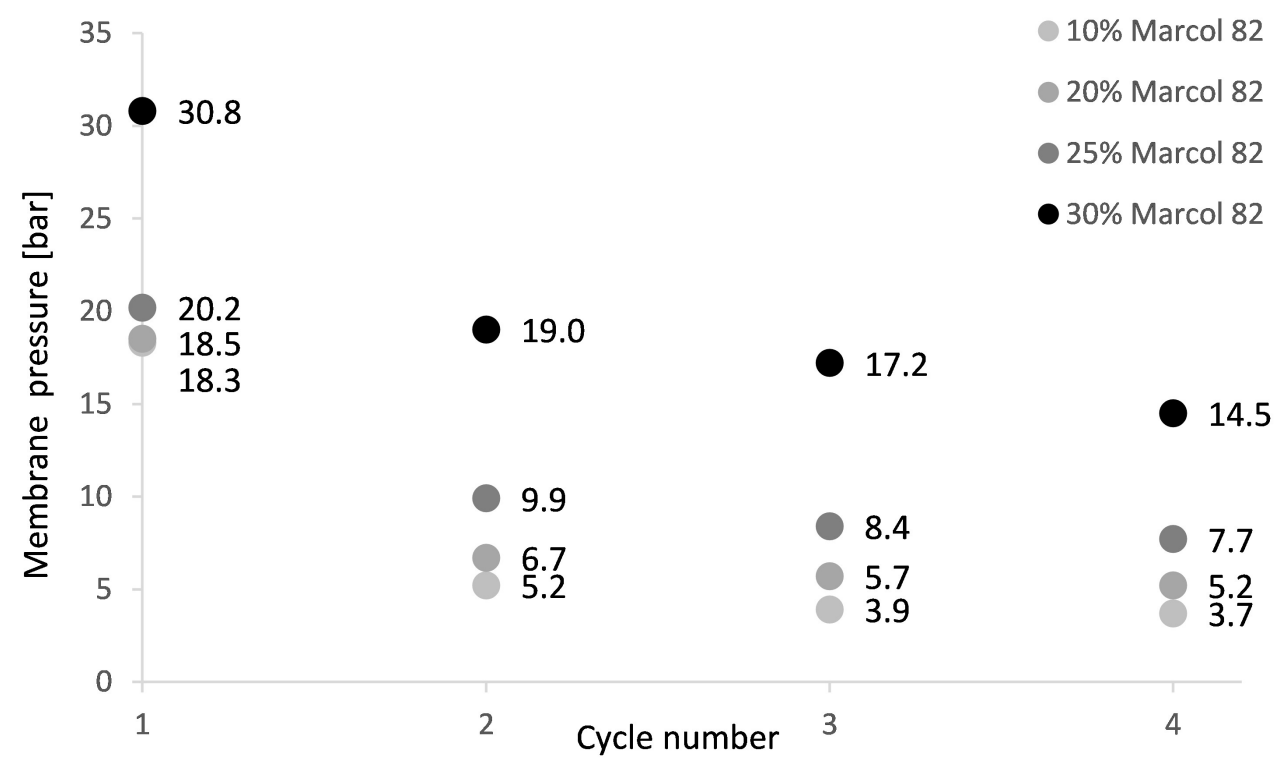

Figure 8: Membrane pressure as a function of cycle number for different Marcol 82 contents at a flowrate of $100 \mathrm{~mL} / \mathrm{min}$

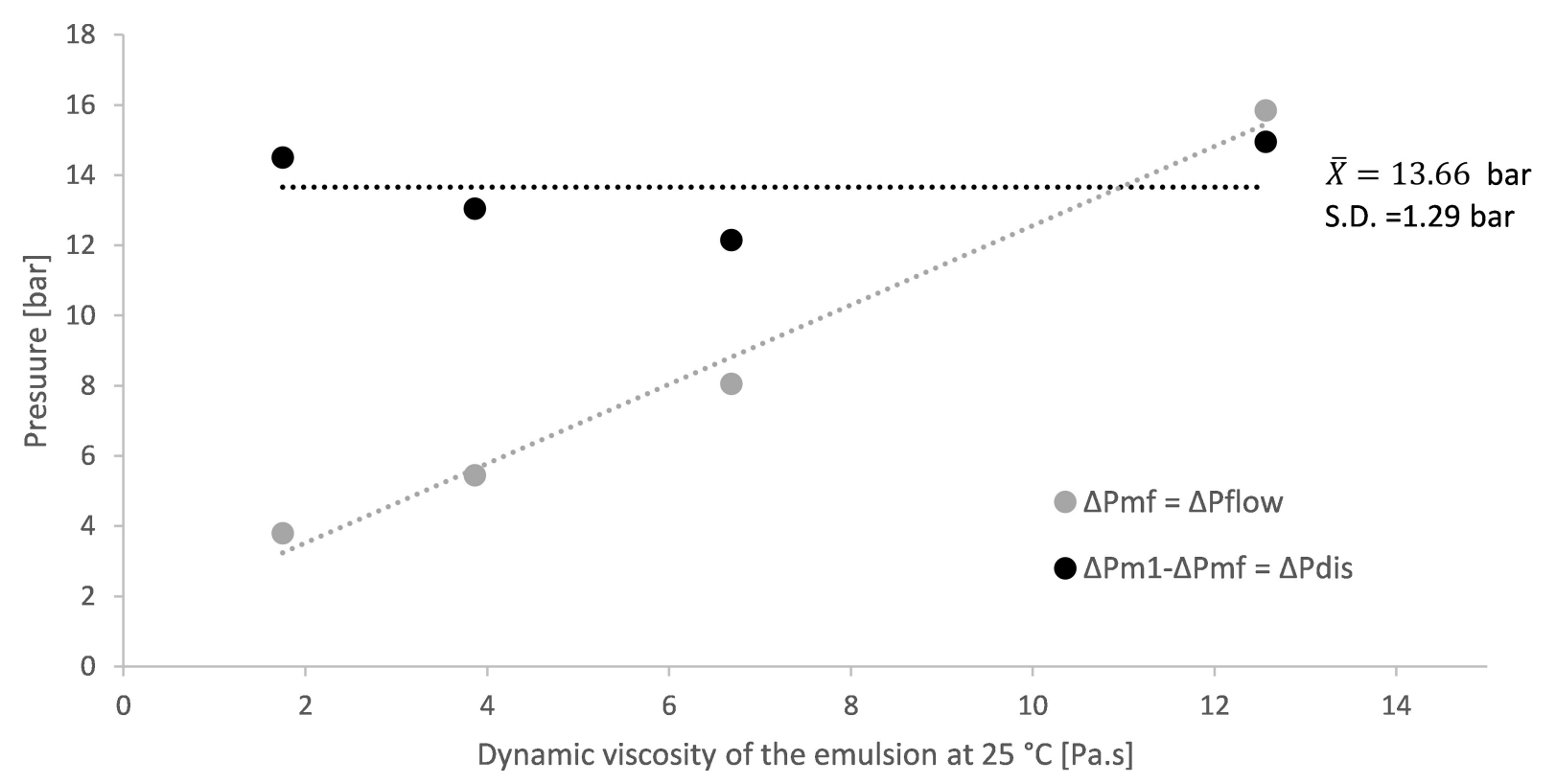

Figure 9: Influence of dynamic emulsion viscosity on $\Delta P_{\text {flow }}$ and $\Delta P_{\text {dis }}$

viscosity as described in Materials and Methods. The membrane pressure was measured for all formulations, while the droplet size was reported only for formulations with different continuous phases. 


\subsubsection{Influence of the continuous phase viscosity}

1. WMO, WMO + Marcol 82, Marcol 82 and Marcol 52. Water and total surfactant concentration were kept constant at $10 \%$ and 5\%, respectively. Figure 10 shows the membrane pressures measured at various flowrates up to $50 \mathrm{~mL} / \mathrm{min}$ except for the more viscous oil WMO where $40 \mathrm{~mL} / \mathrm{min}$ was set to keep the resulting pressure below 65 bar. The membrane pressure was proportional to the flowrate for the four of nanoemulsions production by PME. Indeed, the resulting pressure has to be lower than 65 bar, and the viscosity has a major impact on the membrane pressure. The viscosity is of greater importance for $\mathrm{W} / \mathrm{O}$ nanoemulsions production as higher viscosities are involved.

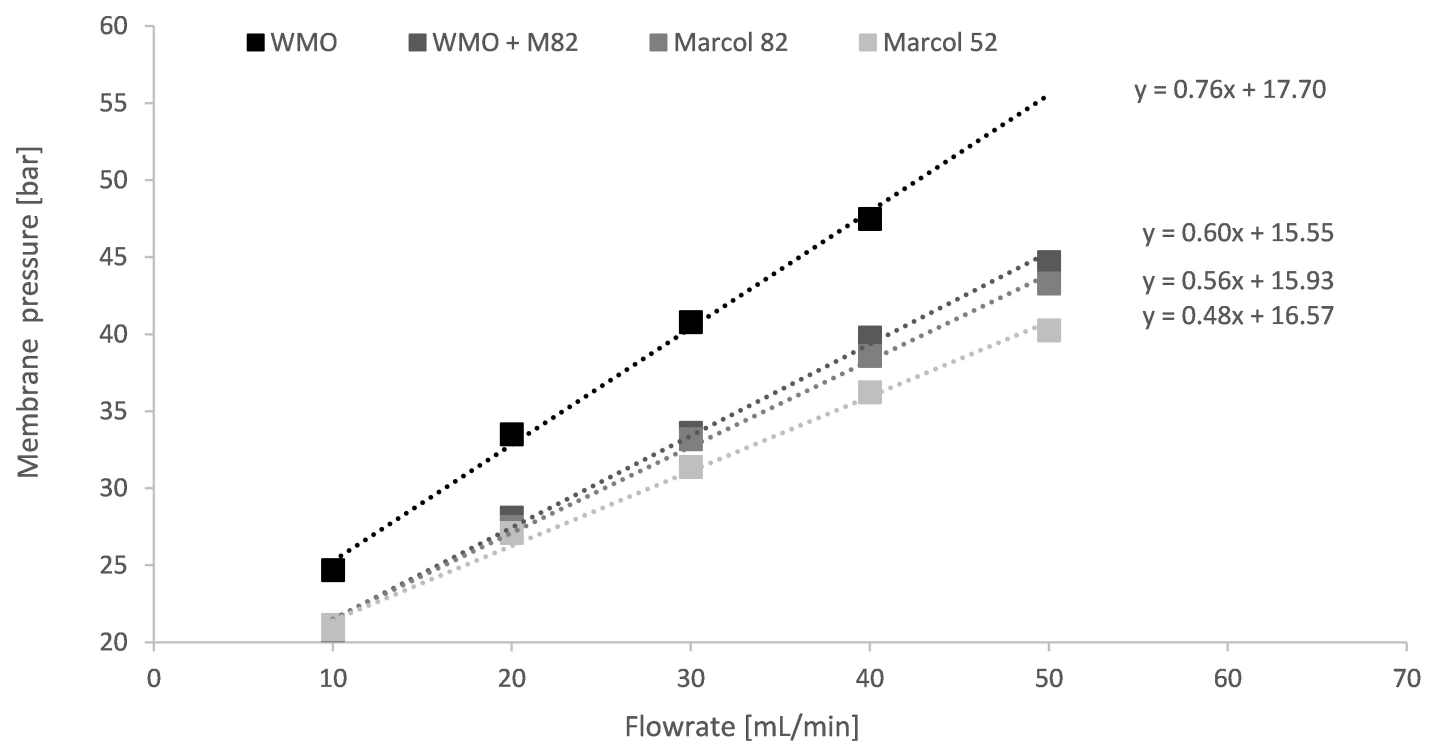

Figure 10: Membrane pressure variation with flowrate for oils of different viscosities as continuous phases with oil and surfactant content kept constant at $10 \%$ and $5 \%$ respectively 


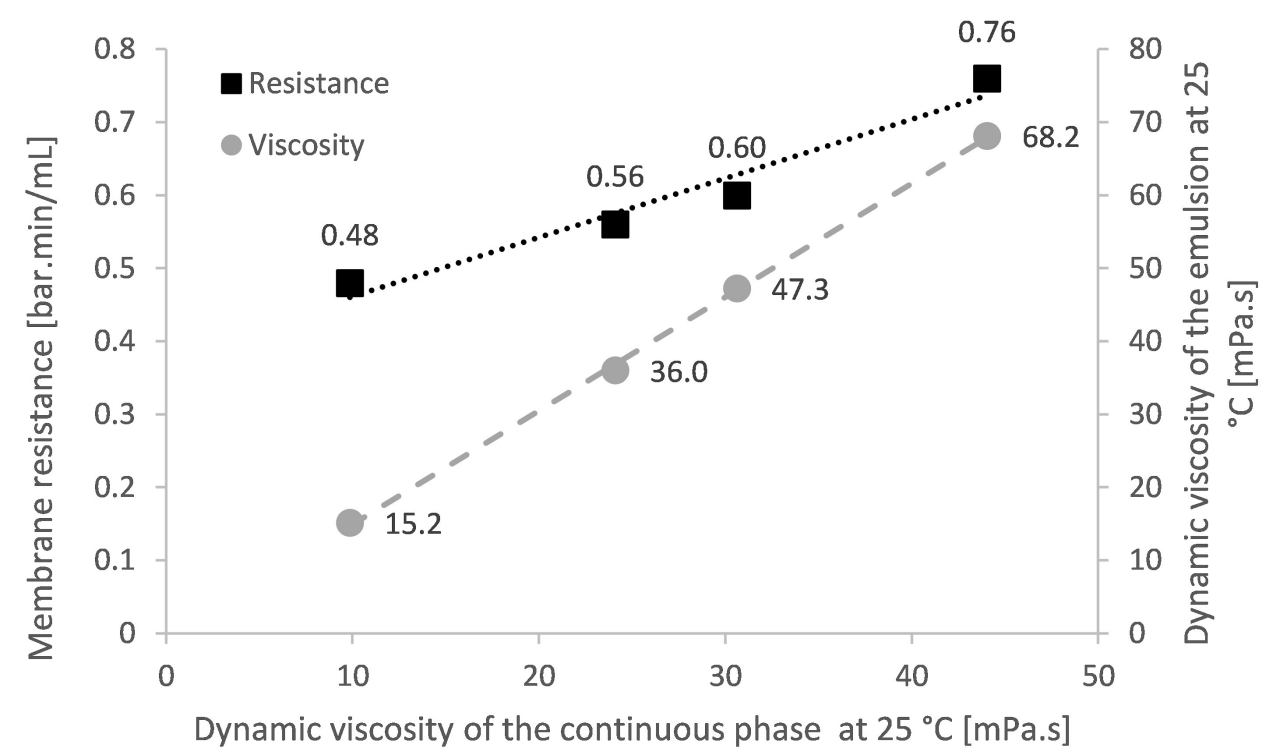

Figure 11: Membrane resistance variation with flowrate and dynamic viscosity of the emulsion as a function of continuous phase viscosity

\subsubsection{Influence of the dispersed phase viscosity}

To investigate the influence of the dispersed phase viscosity, nanoemulsions with five different concentrations of glycerol in the dispersed phase $(0,25,50,75$ and $100 \%)$ were prepared. Figure 12 shows the membrane pressure as function of flowrate for a fixed composition of $10 \%$ dispersed phase, $5 \%$ surfactant and $85 \%$ Marcol 82 as the continuous phase. For concentrations up to 50\% glycerol, the membrane pressure did not change, however, at higher amounts of glycerol 75 and $100 \%$, the membrane pressure values were much lower. Indeed, at high glycerol concentrations, the density of the dispersed phase became higher and so the difference of density between the continuous and dispersed phases might induce sedimentation. It is likely that the premix underwent sedimentation in the high pressure syringe pump and so the injected dispersed phase was less concentrated, which might result in a decrease of the membrane pressure. Indeed, the membrane pressure decreases when decreasing the amount of dispersed phase as seen previously with $\mathrm{O} / \mathrm{W}$ nanoemulsions and observed below for $\mathrm{W} / \mathrm{O}$ nanoemulsions.

In addition, when increasing the glycerol content, the viscosity of the dispersed phase increased to 27.8 $\mathrm{mPa} . \mathrm{s}$ for $75 \%$ glycerol and $905.7 \mathrm{mPa}$.s for $100 \%$ glycerol. The difference in viscosities between the continuous and dispersed phases was lower for $75 \%$ glycerol than for lower concentrations and can explain the decrease in membrane pressure as seen for $\mathrm{O} / \mathrm{W}$ results. However, this effect could not explain the decrease in membrane pressure for $100 \%$ glycerol, where the difference in viscosities was very high. So, it seems that this effect could not explain the difference in membrane pressure observed as it did with $\mathrm{O} / \mathrm{W}$ nanoemulsions.

These results suggest that for both $\mathrm{O} / \mathrm{W}$ and $\mathrm{W} / \mathrm{O}$ nanomulsions the dispersed phase viscosity in PME has not a significant effect. 


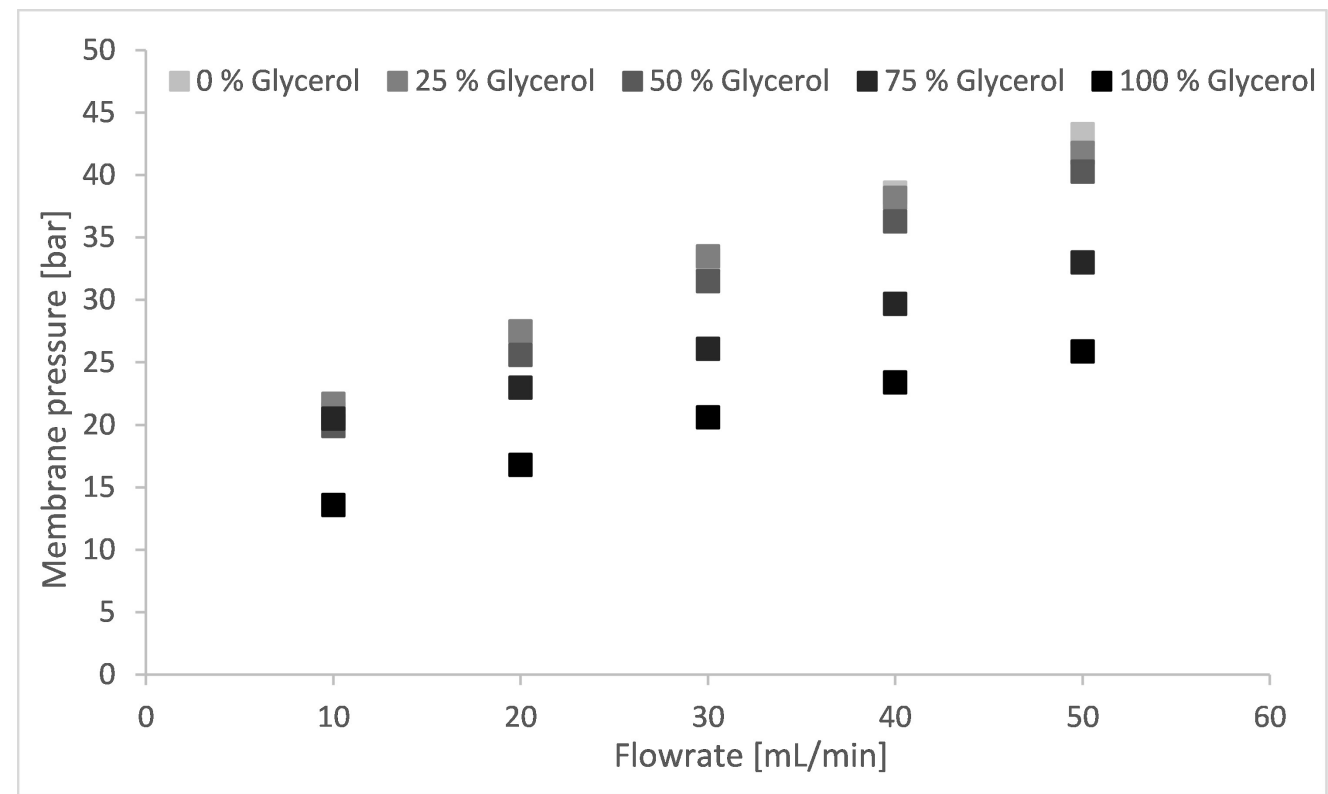

Figure 12: Variation of membrane pressure for different amounts of glycerol in the dispersed phase, with oil and surfactant content kept constant at $10 \%$ and $5 \%$ respectively

\subsubsection{Influence of the dispersed phase content}

The influence of the dispersed phase content was tested for four water concentrations 1, 5, 10 and 15\%. The surfactant to water ratio was kept constant at 0.5 corresponding to surfactant concentrations of respectively $0.5,2.5,5,7.5 \%$. The oil used was Marcol 82 for all experiments. Figure 13 shows the variation of the membrane pressure and emulsion viscosity with the dispersed phase content. The membrane pressure and the dynamic viscosity were a linear function of the water content, at this range of concentrations. However, as shown on Figure 9, for $\mathrm{O} / \mathrm{W}$ nanoemulsions and at a larger range of dispersed phase concentrations, $\Delta P_{m}$ was the addition of a parameter that was highly dependent on viscosity $\Delta P_{\text {flow }}$ and one which was constant $\Delta P_{\text {dis }}$. At our experimental conditions, the membrane pressure increased linearly with the water content; it might be explained by the fact that in this dispersed phase range, viscosity increases linearly with water content. In this case, the membrane pressure is the addition of one term that increase linearly with the water content and one that does not depend on the water content, which explain its linearity.

\subsubsection{Determination of $\Delta P_{\text {flow }}$ and $\Delta P_{\text {dis }}$}

As for $\mathrm{O} / \mathrm{W}$ nanoemulsions, $\Delta P_{\text {flow }}$ and $\Delta P_{\text {dis }}$ were determined from the influence of the cycle number on the membrane pressure. For W/O, one composition was tested: $10 \%$ water, $5 \%$ surfactant and $85 \%$ Marcol 82 , at $50 \mathrm{~mL} / \mathrm{min}$ and the result is presented in Figure 14 . At this composition and for these experimental conditions, the difference in pressure between the first cycle and the stabilized pressure was $\Delta P_{d i s}=\Delta P_{m 1}$ - $\Delta P_{m f}=7.6$ bar and $\Delta P_{\text {flow }}=\Delta P_{m f}=35.7$ bar. $\Delta P_{\text {dis }}$ was lower than for $\mathrm{O} / \mathrm{W}$ nanoemulsions. Indeed, the flowrate was two times lower $(50 \mathrm{~mL} / \mathrm{min}$ for $\mathrm{W} / \mathrm{O}$ and $100 \mathrm{~mL} / \mathrm{min}$ for $\mathrm{O} / \mathrm{W}$ nanoemulsions $) . \Delta P_{\text {dis }}$ 


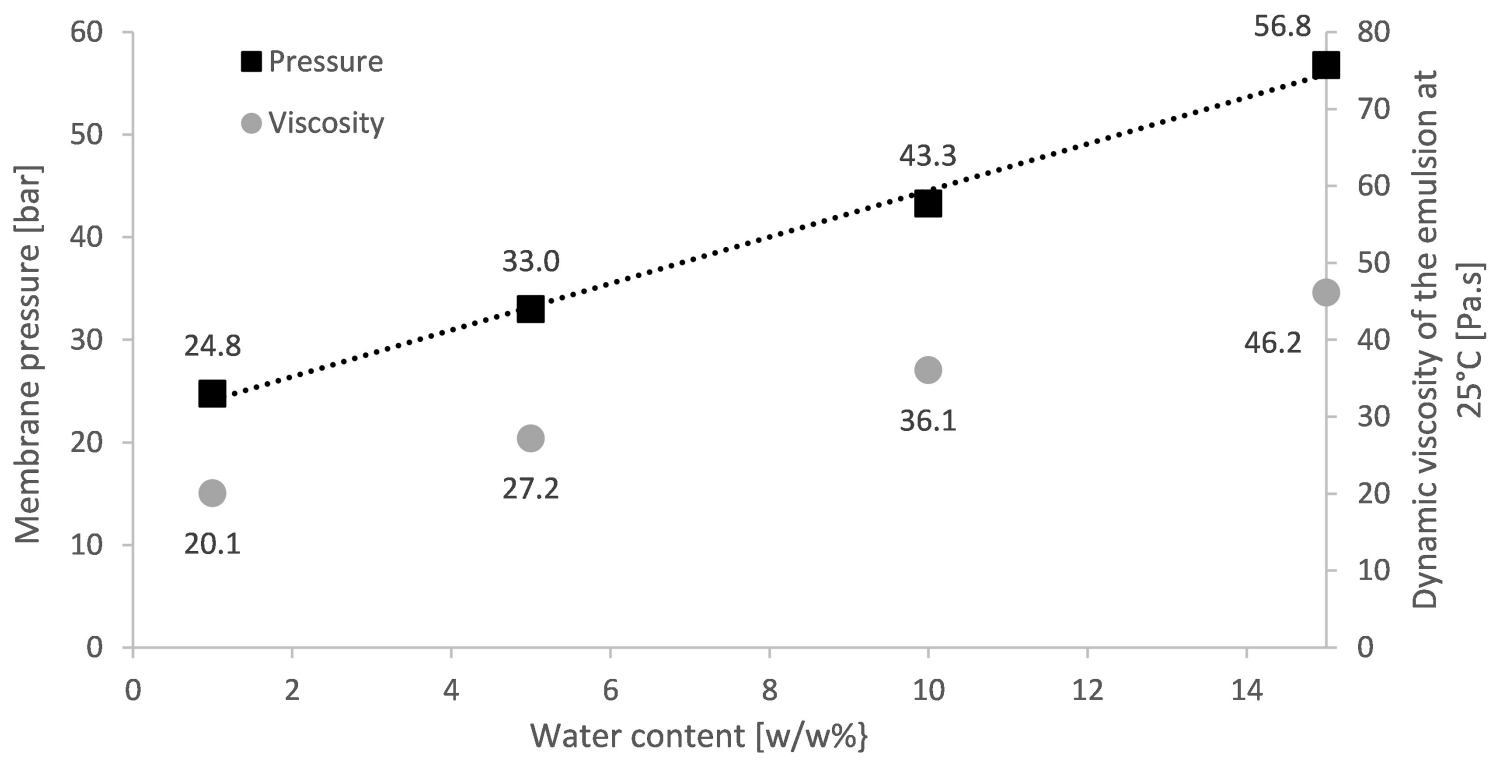

Figure 13: Variation of droplet size and membrane pressure with water content at $50 \mathrm{~mL} / \mathrm{min}$

should decrease when decreasing the flowrate, as suggested by Figure 6 where $\Delta P_{\text {membrane }}$ was equal to 14.7 bar at $50 \mathrm{~mL} / \mathrm{min}$, suggesting a lower value of $\Delta P_{\text {dis }}$ than that obtained at $100 \mathrm{~mL} / \mathrm{min}(14.5 \mathrm{bar})$. Further investigations would be needed to investigate the effect of flowrate on $\Delta P_{d i s}$.

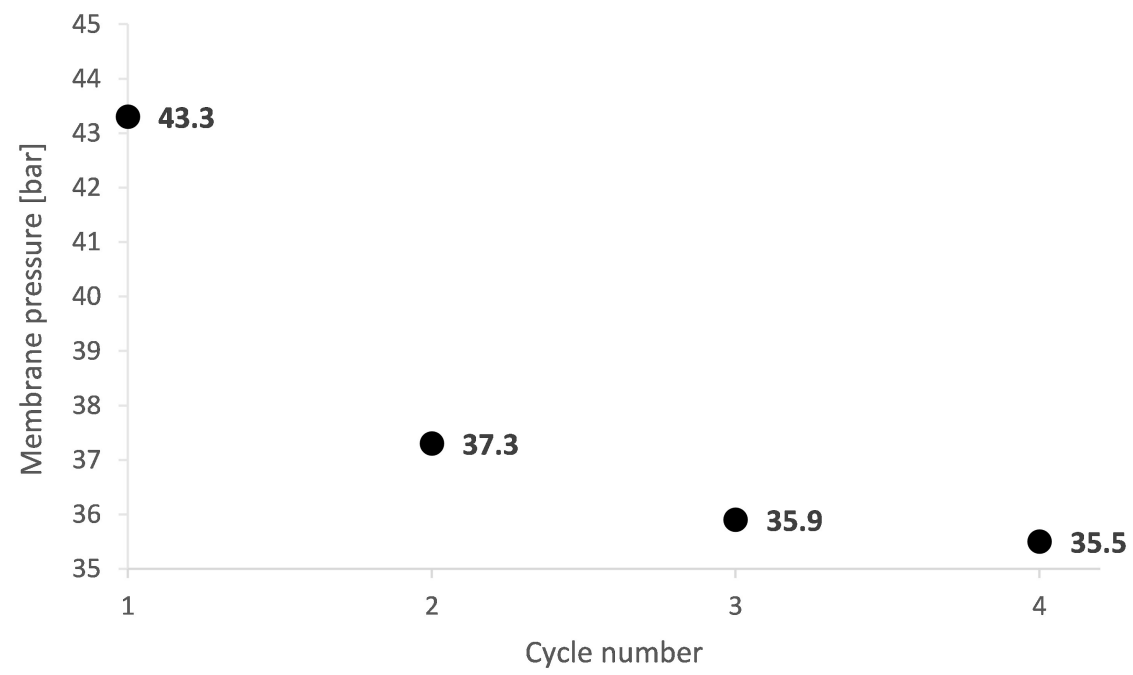

Figure 14: Effect of cylcle number on membrane pressure at a composition of $10 \%$ water, $5 \%$ surfactant and $85 \%$ Marcol 82 at a flowrate of $50 \mathrm{~mL} / \mathrm{min}$ 


\subsubsection{Influence on droplet size distribution}

For $\mathrm{W} / \mathrm{O}$ nanoemulsions, the droplet size measurement with the oil as the continuous phase is much more difficult compared to $\mathrm{O} / \mathrm{W}$ nanoemulsions with water as the continuous phase. Consequently, it was more difficult to see the variation of droplet size. However, droplets size around 550 to $660 \mathrm{~nm}$ were observed by laser diffraction (Figure 15). There was only a little effect of the continuous phase viscosity on the droplet size distribution. D50 decreased when increasing the continuous phase viscosity except for WMO but the nanoemulsions were obtained at a lower flowrate. The effect of the continuous phase viscosity appears less pronounced than for $\mathrm{W} / \mathrm{O}$ nanoemulsions. It could be explained by the lower flowrate used, resulting in lower shear stress, which can affect the influence of the continuous phase viscosity. Also, the droplet sizes showed a broader distribution, and therefore it is more difficult to observe a real effect on the droplet size.

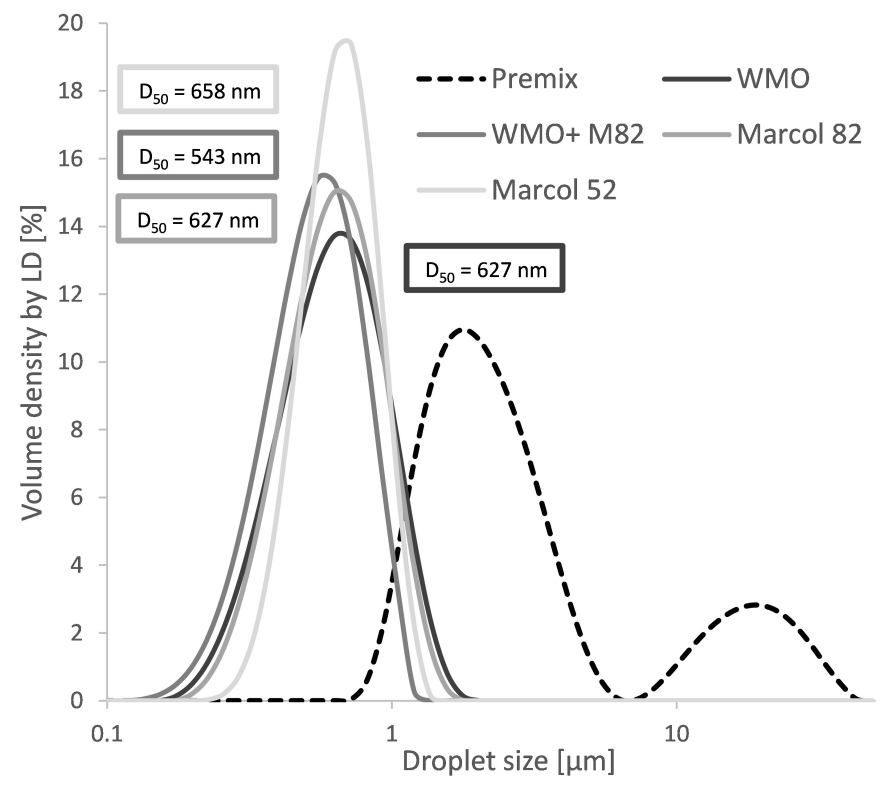

Figure 15: Droplet size distribution of $\mathrm{W} / \mathrm{O}$ nanoemulsions with different oils obtained at $50 \mathrm{~mL} / \mathrm{min}$ except for WMO at 40 $\mathrm{mL} / \mathrm{min}$

\section{Conclusion}

In this study, $\mathrm{O} / \mathrm{W}$ and $\mathrm{W} / \mathrm{O}$ nanoemulsions were prepared successfully by PME and SPG membranes. For that, a controlled set-up including a high pressure syringe and a membrane module in PME mode, developed in our previous study, was used [16]. As the pressure through the membrane must be lower than 65 bar, we investigated the effect of viscosities of the continuous phase, dispersed phase, and dispersed phase content to be able to produce viscous $\mathrm{O} / \mathrm{W}$ and $\mathrm{W} / \mathrm{O}$ nanoemulsions successfully.

The resulting pressure is a key parameter which governs the production of nanoemulsions in PME and is due to three main resistances: the resistance of flow through the pipe connecting the pump to the membrane 
module $\Delta P_{\text {pipe }}$, the resistance of flow through the membrane pores $\Delta P_{\text {flow }}$ and the resistance due to the

\section{References}

[1] A. Mihranyan, N. Ferraz, M. Strømme, Current status and future prospects of nanotechnology in cosmetics, Progress in Materials Science 57 (5) (2012) 875-910. doi:10.1016/j.pmatsci.2011.10.001 URL http://linkinghub.elsevier.com/retrieve/pii/S0079642511001046

[2] H. D. Silva, M. A. Cerqueira, A. A. Vicente, Nanoemulsions for Food Applications: Development and Characterization, Food and Bioprocess Technology 5 (3) (2012) 854-867. doi:10.1007/ s11947-011-0683-7.

URL http://link.springer.com/10.1007/s11947-011-0683-7

¿ [3] F. Shakeel, W. Ramadan, Transdermal delivery of anticancer drug caffeine from water-in-oil nanoemul- 
09.010 .

URL http://linkinghub.elsevier.com/retrieve/pii/S0927776509004202

[4] H. Wu, C. Ramachandran, N. D. Weiner, B. J. Roessler, Topical transport of hydrophilic compounds using water-in-oil nanoemulsions, International Journal of Pharmaceutics 220 (1-2) (2001) 63-75.

415 [5] M. Iqbal, N. Zafar, H. Fessi, A. Elaissari, Double emulsion solvent evaporation techniques used for

口. drug encapsulation, International Journal of Pharmaceutics 496 (2) (2015) 173-190. doi:10.1016/j. ijpharm.2015.10.057.

URL http://linkinghub.elsevier.com/retrieve/pii/S0378517315303264

口 [6] M. N. Yukuyama, D. D. M. Ghisleni, T. J. A. Pinto, N. A. Bou-Chacra, Nanoemulsion: process selection and application in cosmetics - a review, International Journal of Cosmetic Science (2015) n/a-n/adoi: $10.1111 /$ ics.12260

URL http://doi.wiley.com/10.1111/ics.12260

[7] C. Solans, P. Izquierdo, J. Nolla, N. Azemar, M. Garciacelma, Nano-emulsions, Current Opinion in Colloid \& Interface Science 10 (3-4) (2005) 102-110. doi:10.1016/j.cocis.2005.06.004

URL http://linkinghub.elsevier.com/retrieve/pii/S1359029405000348

[8] C. Charcosset, Membranes for the preparation of emulsions and particles, in: Membrane Processes in Biotechnology and Pharmaceutics, Elsevier, Ed. C. Charcosset,, 2012, pp. 213-251.

URL http://linkinghub.elsevier.com/retrieve/pii/B978044456334700006X

[ [9] G. T. Vladisavljević, Structured microparticles with tailored properties produced by membrane emulsification, Advances in Colloid and Interface Science 225 (2015) 53-87. doi:10.1016/j.cis.2015.07.013. URL http://linkinghub.elsevier.com/retrieve/pii/S000186861500144X

[10] S. Joseph, H. Bunjes, Evaluation of Shirasu Porous Glass (SPG) membrane emulsification for the preparation of colloidal lipid drug carrier dispersions, European Journal of Pharmaceutics and Biopharmaceutics 87 (1) (2014) 178-186. doi:10.1016/j.ejpb.2013.11.010. URL http://linkinghub.elsevier.com/retrieve/pii/S0939641113003822

[11] A. Nazir, K. Schroën, R. Boom, Premix emulsification: A review, Journal of Membrane Science 362 (1-2) (2010) 1-11. doi:10.1016/j.memsci.2010.06.044. URL http://linkinghub.elsevier.com/retrieve/pii/S0376738810005119

[12] G. Vladisavljević, M. Shimizu, T. Nakashima, Preparation of monodisperse multiple emulsions at high production rates by multi-stage premix membrane emulsification, Journal of Membrane Science 244 (1-2) (2004) 97-106. doi:10.1016/j.memsci.2004.07.008. URL http://linkinghub.elsevier.com/retrieve/pii/S0376738804005058 
[13] G. T. Vladisavljević, U. Lambrich, M. Nakajima, H. Schubert, Production of O/W emulsions using SPG membranes, ceramic $\alpha$-aluminium oxide membranes, microfluidizer and a silicon microchannel plate a comparative study, Colloids and Surfaces A: Physicochemical and Engineering Aspects 232 (2-3) (2004) 199-207. doi:10.1016/j.colsurfa.2003.10.026.

URL http://linkinghub.elsevier.com/retrieve/pii/S0927775703006137

[14] S. Gehrmann, H. Bunjes, Instrumented small scale extruder to investigate the influence of process parameters during premix membrane emulsification, Chemical Engineering Journal 284 (2016) 716-723. doi:10.1016/j.cej.2015.09.022.

URL http://linkinghub.elsevier.com/retrieve/pii/S1385894715012796

[15] S. Gehrmann, H. Bunjes, Preparation of nanoemulsions by premix membrane emulsification: which parameters have a significant influence on the resulting particle size?, Journal of Pharmaceutical Sciences 106 (8) (2017) 2068-2076. doi:10.1016/j.xphs.2017.04.066 URL http://linkinghub.elsevier.com/retrieve/pii/S0022354917303374

[16] O. Alliod, J.-P. Valour, S. Urbaniak, H. Fessi, D. Dupin, C. Charcosset, Preparation of oil-in-water nanoemulsions at large-scale using premix membrane emulsification and Shirasu Porous Glass (SPG) mem-

branes, Colloids and Surfaces A: Physicochemical and Engineering Aspectsdoi:10.1016/j.colsurfa. 2018.04 .045 URL http://linkinghub.elsevier.com/retrieve/pii/S0927775718303212

[17] G. T. Vladisavljević, M. Shimizu, T. Nakashima, Production of multiple emulsions for drug delivery a systems by repeated SPG membrane homogenization: Influence of mean pore size, interfacial tension q and continuous phase viscosity, Journal of Membrane Science 284 (1-2) (2006) 373-383. doi:10.1016/ j.memsci.2006.08.003. URL http://linkinghub.elsevier.com/retrieve/pii/S0376738806005370

[18] P. S. Silva, V. M. Starov, R. G. Holdich, Membrane emulsification: Formation of water in oil emulsions using a hydrophilic membrane, Colloids and Surfaces A: Physicochemical and Engineering Aspects 532 (2017) 297-304. doi:10.1016/j.colsurfa.2017.04.077.

URL http://linkinghub.elsevier.com/retrieve/pii/S0927775717304181

470 [19] P. S. Silva, S. Morelli, M. M. Dragosavac, V. M. Starov, R. G. Holdich, Water in oil emulsions from ם hydrophobized metal membranes and characterization of dynamic interfacial tension in membrane emulsification, Colloids and Surfaces A: Physicochemical and Engineering Aspects 532 (2017) 77-86. doi:10.1016/j.colsurfa.2017.06.051.

URL http://linkinghub.elsevier.com/retrieve/pii/S0927775717306131

475 [20] C.-J. Cheng, L.-Y. Chu, R. Xie, Preparation of highly monodisperse W/O emulsions with hydrophobically modified SPG membranes, Journal of Colloid and Interface Science 300 (1) (2006) 375-382. 
doi:10.1016/j.jcis.2006.03.056.

URL http://linkinghub.elsevier.com/retrieve/pii/S0021979706002451

[21] K. Kandori, K. Kishi, T. Ishikawa, Preparation of monodispersed W/O emulsions by Shirasu-porousglass filter emulsification technique, Colloids and surfaces 55 (1991) 73-78.

[22] G. T. Vladisavljević, S. Tesch, H. Schubert, Preparation of water-in-oil emulsions using microporous polypropylene hollow fibers: influence of some operating parameters on droplet size distribution, Chemical Engineering and Processing: Process Intensification 41 (3) (2002) 231-238.

[23] S. van der Graaf, C. G. P. H. Schroën, R. M. Boom, Preparation of double emulsions by membrane emulsification a review, Journal of Membrane Science 251 (1-2) (2005) 7-15. doi:10.1016/j .memsci. 2004.12 .013

URL http://linkinghub.elsevier.com/retrieve/pii/S0376738804008312

[24] G. Vladisavljević, M. Shimizu, T. Nakashima, Permeability of hydrophilic and hydrophobic Shirasuporous-glass (SPG) membranes to pure liquids and its microstructure, Journal of Membrane Science 250 (1-2) (2005) 69-77. doi:10.1016/j.memsci.2004.10.017.

URL http://linkinghub.elsevier.com/retrieve/pii/S0376738804007112

[25] S. H. Silalahi, T. Leiknes, Cleaning strategies in ceramic microfiltration membranes fouled by oil and particulate matter in produced water, Desalination 236 (1-3) (2009) 160-169. doi:10.1016/j.desal. 2007.10 .063 . URL http://linkinghub.elsevier.com/retrieve/pii/S0011916408006395

[26] D. R. Link, S. L. Anna, D. A. Weitz, H. A. Stone, Geometrically mediated breakup of drops in microfluidic devices, Phys. Rev. Lett. 92 (2004) 054503. doi:10.1103/PhysRevLett.92.054503.

URL https://link.aps.org/doi/10.1103/PhysRevLett.92.054503

[27] E. van der Zwan, K. Schroën, K. van Dijke, R. Boom, Visualization of droplet break-up in pre-mix membrane emulsification using microfluidic devices, Colloids and Surfaces A: Physicochemical and Engineering Aspects 277 (13) (2006) 223-229. doi:10.1016/j.colsurfa.2005.11.064

URL http://www.sciencedirect.com/science/article/pii/S092777570500912X

[28] S. van der Graaf, C. Schroën, R. van der Sman, R. Boom, Influence of dynamic interfacial tension on droplet formation during membrane emulsification, Journal of Colloid and Interface Science 277 (2) (2004) 456-463. doi:10.1016/j.jcis.2004.04.033.

URL http://linkinghub.elsevier.com/retrieve/pii/S0021979704003972

[29] G. T. Vladisavljević, Integrated membrane processes for the preparation of emulsions, particles and bubbles, in: Integrated Membrane Systems and Processes, Wiley, Eds A.Basile, C. Charcosset, 2015, p. 79 . 
URL http://books.google.com/books?hl=en\&lr=\&id=TB1cCwAAQBAJ\&oi=fnd\&pg=PA79\&dq=\%22I+

1 into+phase+II.+Membrane+treatment+of+dispersions+(Figure+5.1c)+involves $\% 22+\% 22$ the+

1 feed+dispersion+through+the+membrane, +which+results+in+the+modi\%EF\%AC\%81cation+of $\% 22+$

\%22et+al . , +2004) .+A+shear+is+applied+at+the+membrane/continuous+phase+interface\%22+ \&ots=U1JXgp4FL6\&sig=-fx78ejxLIasBr8Xa6z0X9R-DS0 